\title{
Study on Psychological Stress and Life Behavior of College Students During COVID-19 Epidemic
}

\author{
Yuhan Zhan ${ }^{1}$, Junhua Zhang ${ }^{1, *}$ \\ ${ }^{1}$ Tsinghua University, Beijing, China, 100084 \\ ${ }^{1}$ University of Utah, Salt Lake City, United States, 84111 \\ *Corresponding author. Email: zhujinghuige@gmail.com
}

\begin{abstract}
During the epidemic of Covid-19, under the combined effects of the fear of infection, academic workload and emotional pressure, college students are facing greater psychological stress than before. College students, a special group that has just transitioned to adulthood, have an unique psychological status, which has attracted extensive attention. Because of the varying living environment and cultural background, there may be distinct psychological differences between domestic and overseas college students. The purpose of this study is to compare and analyze the similarities and differences of psychological stress between domestic and overseas college students in the Covid-19 epidemic, quantify the correlation between psychological stress and personal behaviors. Professor Yang Ting Zhong's revised stress perception scale was used to quantitatively evaluate the psychological stress of the interviewees. Taking domestic college students and overseas college students as research subjects, this project investigates the psychological stress of college students during the epidemic. The questionnaire designed by the author mainly includes six parts: basic information collection, psychological pressure perception evaluation, the attention to the epidemic information, the behavior of mask wearing, study and entertainment, as well as social activities. Then the statistical analysis of collected data was performed. In this study, 140 domestic college students and 81 overseas college students were interviewed. The psychological stress of the subjects was measured by CPSS scale. The correlation between psychological stress and various behaviors of college students was analyzed. The research found that the behaviors such as consistent mask wearing, moderate understanding of epidemic progress, active involvement in the extracurricular activities and interaction with family members, effectively alleviated the psychological pressure of college students.
\end{abstract}

Keywords: psychological stress, life behavior, college students, Covid-19

\section{INTRODUCTION}

Since the beginning of 2020, the Covid-19 epidemic has swept the world, disrupting the economy and social life [1]. In order to contain the spread of the virus, many countries have taken measures such as social distancing and closing public places, including schools.

College students' interpersonal communication is characterized by greater universality, interactivity and diversity. The epidemic inevitably transfers psychological pressure to college students. The accumulation of anxiety or stress endangers the mental health of this group. Therefore it is of great significance to study and analyze the psychological stress and life behavior of domestic college students during the epidemic. Under the multiplex impacts of complex epidemic evolution and local cultural habits, the differences of psychological stress between overseas and domestic college students are also worth exploring.

The research on the influence of college students' psychological stress has mainly focused on objective factors such as gender, age, family status, and a few behavioral factors related to the received epidemic information. For example, Chang Jinghui's research found that non-medical majors living in rural areas with more than half of the information about the epidemic situation being negative were prone to develop anxiety [2]. Women with a history of alcohol use who lived in the suburbs who received more than half of the epidemic information being negative were predisposed to depression. The research of Wang Ya et al. demonstrated a significant correlation between anxiety level of college students during the epidemic and gender, education background, major and daily internet surfing time [3]. A 
more comprehensive behavioral study will be valuable and instructive. College students in the "new adult" period [4] with relative sensitive mood and volatility to environmental factors, are one of the most vulnerable population [5].

This study is expected to compare the psychological stress of college students at home and abroad, and find out the most likely causes of anxiety, ways of stress relief and the coping methods by investigating the relationship of psychological stress and life behavior of college students. Our research may be helpful to domestic / overseas college students who are over-stressed or institutions concerned about students' mental health.

\section{RESEARCH SUBJECTS AND METHODS}

\subsection{Research Subjects}

This study took domestic college students and overseas college students as research subjects, and investigated their psychological stress during the epidemic and its correlation with different life behaviors. The survey selected 140 college students from Chinese universities and 81 overseas Chinese students from American, British, Canadian and Australian universities. Students with history of psychological diseases were excluded. In the investigation stage from March 14th, 2020 to April 7th, 2020, a survey on life behavior and stress perception was conducted among college students at home and abroad, and then the characteristics of life behavior and psychological stress scores were statistically analyzed, and the correlation between them was calculated.

\subsection{Research Methods}

This scale uses the pressure perception scale revised by Professor Yang Ting Zhong, or CPSS (Chinese perceived Stress Scale) for short, to assess the psychological stress of college students during the epidemic. There are 14 questions in the scale, which stratify the psychological stress of the respondents from two dimensions: tension and controllability. Out of the 14 questions, 7 questions are scored forwardly, which have $1,2,3,8,11,12$ and 14 points respectively. The remaining 7 items are scored reversely with the 1-5 rating scale. The higher score corresponds to higher individual pressure. 14 42 points (average 1-3) indicates normal pressure. 43 56 points (average 3-4) suggests moderate stress. 57-70 points (average 4-5) defines severe stress. The reliability of the scale is 0.76 , and the internal consistency coefficient is 0.75 . It is widely used in psychological stress assessment research [6].
The questionnaire of life behavior was designed by the author and mainly encompassed six sections: basic information collection, psychological pressure perception evaluation, the attention to epidemic information, mask wearing, study and entertainment, social activities. Then the collected data were cross-analyzed and discussed. In this study, the attention to epidemic information, mask wearing, study and entertainment, social activities were selected as the study variables. Due to the mortality and morbidity related to the epidemic, the duration of focusing on the epidemic information may result in varying levels of panic and anxiety. The authenticity of news reports strongly dependent on the reliability of media channel may also influence the audience's mood. Due to the sudden outbreak of epidemic and the scarcity of masks, the lack of masks may accentuate the psychological stress. On the contrary, appropriate personal precaution may relieve psychological stress. In addition, students' academic workload and panic in the epidemic situation may interact with each other. Whether psychological stress can be effectively alleviated is also an question of interest in this study.

In order to ensure the authenticity and validity of the collected information, bilingual overseas questionnaire was used to avoid language related misinterpretation. This study employed SPSS20 for data analysis. Qualitative data were described by frequency and percentage. Quantitative data were expressed by ratio. The difference of research data between domestic college students and overseas students was analyzed by independent sample $\mathrm{T}$ test using $\mathrm{P}<0.05$ as the cutoff for significant difference.

\section{RESULTS}

Based on the survey result, the CPSS scores of students from different grades of colleges and universities during the epidemic were summarized in Table 1 below. Table 1demonstrated that during the epidemic, the average CPSS scores of students from different grades of colleges and universities all point to moderate stress. The CPSS score of freshmen was slightly lower than that of senior undergraduate students. The "moderate stress" was mostly endorsed among the students, $50.8 \%$ and $52.8 \%$ in freshman and seniors respectively. It was followed by "normal pressure", with $47.5 \%$ and $47.2 \%$ respectively. $74.4 \%$ of domestic postgraduates marked "normal pressure". In contrast, $45.7 \%$ overseas Chinese graduate students indicated "moderate stress". Overall, the psychological pressure of college students during the epidemic was relatively prevalent, but it is generally within control. 
Table 1. CPSS scores of college students from different grades during the epidemic

\begin{tabular}{|c|c|c|l|c|c|c|}
\hline Grades & $\begin{array}{c}\text { Total number } \\
\text { of people }\end{array}$ & $\begin{array}{c}\text { CPSS } \\
\text { score }\end{array}$ & $\begin{array}{c}\text { Pressure } \\
\text { perception }\end{array}$ & $\begin{array}{c}\text { Number of people } \\
\text { with [1,3] points }\end{array}$ & $\begin{array}{c}\text { Number of } \\
\text { people with } \\
{[3,4] \text { points }}\end{array}$ & $\begin{array}{c}\text { Number of people } \\
\text { with [4,5] points }\end{array}$ \\
\hline Domestic freshmen & 61 & 3.08 & moderate stress & 28 & 32 & 1 \\
\hline $\begin{array}{c}\text { Domestic senior } \\
\text { undergraduates }\end{array}$ & 36 & 3.10 & moderate stress & 17 & 19 & 0 \\
\hline $\begin{array}{c}\text { Domestic graduate } \\
\text { students }\end{array}$ & 43 & 2.87 & normal pressure & 32 & 11 & 10 \\
\hline $\begin{array}{c}\text { Overseas Chinese } \\
\text { freshmen }\end{array}$ & 22 & 2.88 & normal pressure & 11 & 8 & 1 \\
\hline $\begin{array}{c}\text { Overseas Chinese } \\
\text { senior undergraduate } \\
\text { students }\end{array}$ & 24 & 2.82 & normal pressure & 16 & 15 & 0 \\
\hline $\begin{array}{c}\text { Overseas Chinese } \\
\text { postgraduate } \\
\text { students }\end{array}$ & 35 & 3.08 & moderate stress & 19 & 15 & 1 \\
\hline
\end{tabular}

In Table 2, the difference analysis of pressure perception between domestic college students and overseas college students. The pressure perception between domestic college students and overseas college students has significant differences in news channels.
There was no significant difference in grade, mask wearing, study time, hobby, communication with family members, number of close friends, participation in community or volunteer activities.

Table 2. Analysis of the difference of pressure perception between domestic and overseas college students

\begin{tabular}{|c|c|c|c|c|}
\hline CPSS & $\begin{array}{c}\text { Domestic college } \\
\text { students }\end{array}$ & $\begin{array}{c}\text { Overseas college } \\
\text { students }\end{array}$ & $t$ & $p$ \\
\hline Grade & $2.98 \pm 0.13$ & $2.96 \pm 0.15$ & 0.124 & 0.905 \\
\hline News channel & $3.03 \pm 0.13$ & $2.14 \pm 1.31$ & 1.66 & 0.001 \\
\hline Mask wearing & $3.07 \pm 0.97$ & $2.90 \pm 0.19$ & 1.62 & 0.25 \\
\hline Study time & $3.04 \pm 0.30$ & $2.90 \pm 0.09$ & 0.89 & 0.15 \\
\hline Hobby & $3.21 \pm 0.29$ & $3.01 \pm 0.16$ & 1.16 & 0.409 \\
\hline $\begin{array}{c}\text { Communication with } \\
\text { family }\end{array}$ & $3.07 \pm 0.09$ & $2.96 \pm 0.25$ & 0.876 & 0.407 \\
\hline $\begin{array}{c}\text { Number of close } \\
\text { friends }\end{array}$ & $3.01 \pm 0.05$ & $2.88 \pm 0.17$ & 1.25 & 0.28 \\
\hline $\begin{array}{c}\text { Community activities } \\
\text { Volunteer activities }\end{array}$ & $3.03 \pm 0.11$ & $2.91 \pm 0.09$ & 1.13 & 0.376 \\
\hline
\end{tabular}

\subsection{Psychological stress and attention to epidemic information}

From Figure 1, it can be seen that, on average, college students watched or read epidemic news for about 0-3 hours every day. Among the freshmen and graduate students in China, 0-1 hour per day was dominant, followed by 1-3 hours and 3-6 hours. Almost nobody spent more than 6 hours on epidemic news on a daily basis. Among domestic undergraduate seniors, domestic graduate students, overseas freshmen, and overseas undergraduate seniors, the largest pie went to 1-3 hours, which was slightly more than $0-1$ hours, followed by 3-6 hours, and again close to zero for more than 6 hours. The vast majority of domestic graduate students spent 1-3 hours on epidemic news every day, with the other duration negligible. 


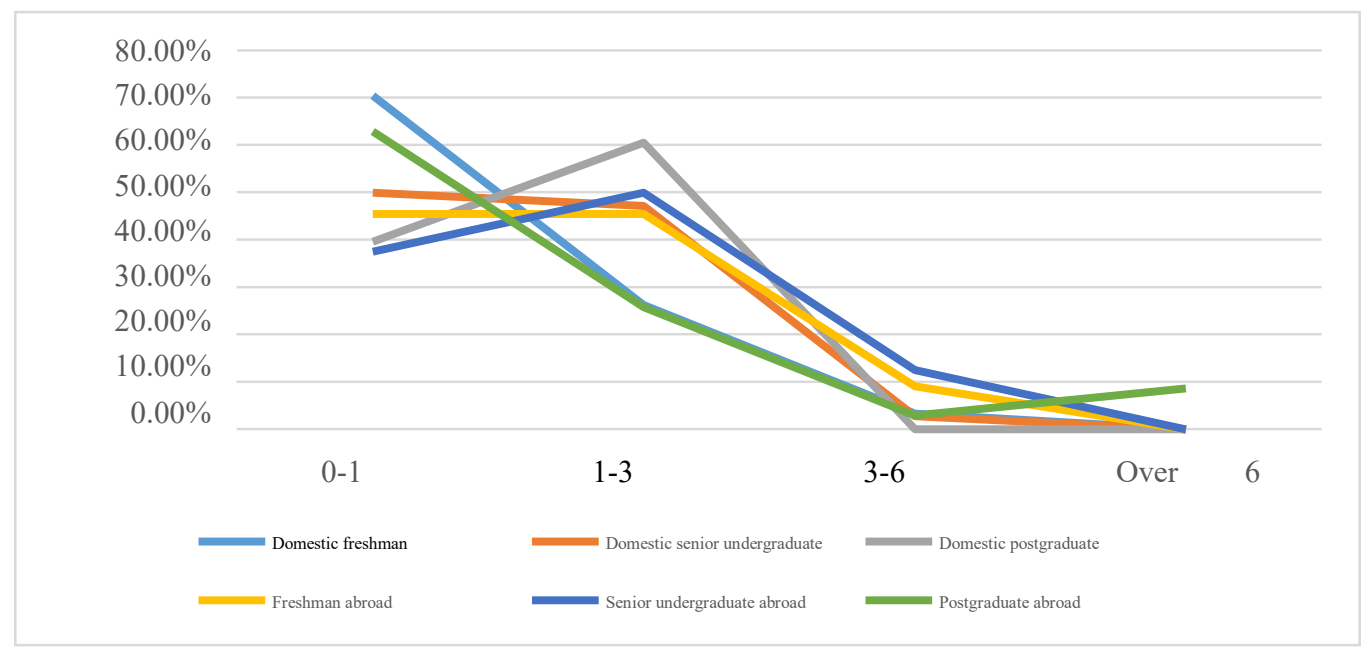

Figure 1 Daily news duration of college students during the epidemic.

Table 3 below shows that, the channels for college students to approach the epidemic news at home and abroad were notably different. Domestic students learned the epidemic progress mainly through CCTV news (71.43\%), webpages $(81.43 \%)$ and we media $(73.57 \%)$. A large proportion of information also came from relatives, friends and community. The contribution of newspapers was relatively small but present. Overseas students learn the epidemic news mainly through we media. CCTV news and internet news also accounted for a relatively big part. The community, relatives and friends, and newspapers were hardly involved.

Table 3. News channels (multiple choices) and CPSS scores of college students

\begin{tabular}{|c|c|c|c|c|c|c|}
\hline News channel & Community & CCTV news & Webpage & $\begin{array}{c}\text { We media (WeChat, } \\
\text { Weibo, etc.) }\end{array}$ & $\begin{array}{l}\text { Relatives and } \\
\text { friends }\end{array}$ & Newspaper \\
\hline $\begin{array}{c}\text { Proportion of } \\
\text { domestic students }\end{array}$ & $16.43 \%$ & $71.43 \%$ & $81.43 \%$ & $73.57 \%$ & $38.57 \%$ & $11.43 \%$ \\
\hline CPSS score & 2.86 & 3.00 & 3.01 & 3.02 & 3.05 & 3.25 \\
\hline $\begin{array}{c}\text { Proportion of } \\
\text { overseas students }\end{array}$ & $1.23 \%$ & $27.16 \%$ & $28.4 \%$ & $41.98 \%$ & $1.23 \%$ & 0 \\
\hline CPSS score & 1.00 & 2.95 & 2.83 & 3.05 & 3.00 & 0 \\
\hline
\end{tabular}

In Figure 2, the self-assessment survey on the influence of students' attention to news on anxiety was different between domestic and overseas students. Based on the responses of the domestic students, only $22.86 \%$ of the respondents thought that knowledge of epidemic could relieve anxiety and help them relax. Half (50\%) of the students reported no obvious influence. $27.14 \%$ of the

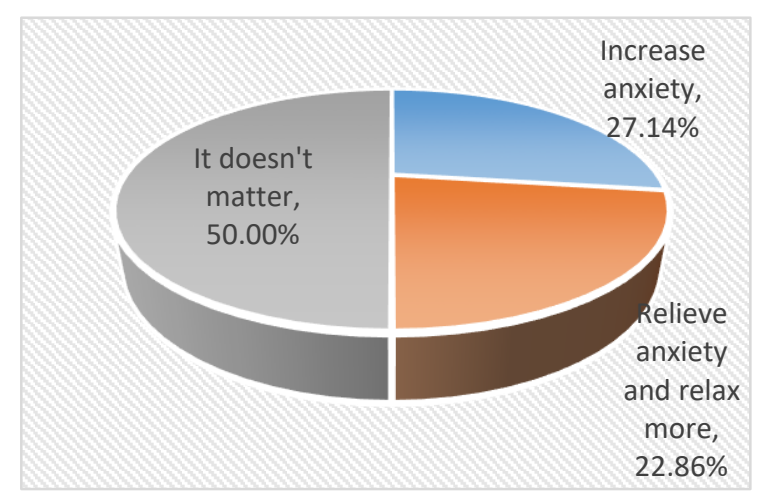

(a) Analysis of domestic college students students found that news update aggravated their anxiety. According to the feedback of overseas students, there is a comparable number of people who believing in that attention to news will aggravate worries or relieve anxiety, accounting for $39.51 \%$ and $38.27 \%$ respectively. $22.22 \%$ of students considered the impact of news and various information insubstantial on their emotions.

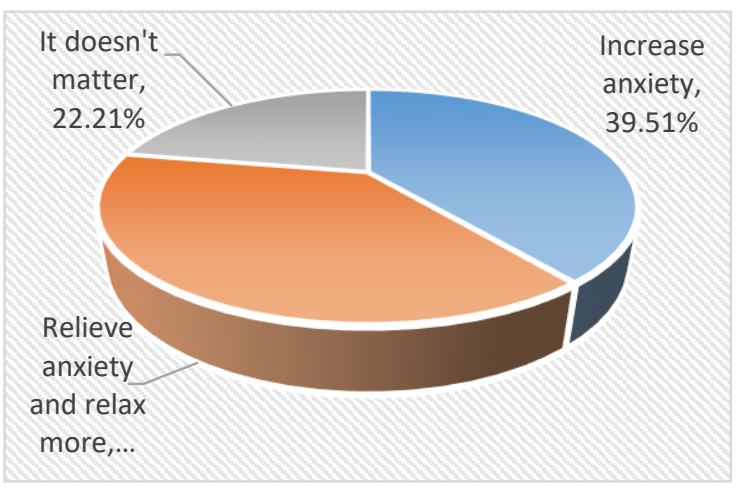

(b) Analysis of overseas college students

Figure 2 The influence of news on psychological stress 


\subsection{Psychological stress and mask wearing}

For college students at home and abroad, the relationship between mask wearing and psychological stress tends to be consistent. For "always wear" and "sometimes wear" groups, the psychological stress index CPSS of college students at home and abroad was very low and lower than the average score. Those who had adequate supply but did not wear them frequently acknowledged higher psychological stress indices, which were 3.21 and 3.18 respectively. It is noteworthy that a subgroup of overseas college students who had extremely limited access to masks and could not afford to wear masks consistently showed a pretty low CPSS index of 2.71, which was way lower than the CPSS score of the group with sufficient masks but not wearing them. (Table 4)

Table 4. Psychological stress and mask wearing

\begin{tabular}{|c|c|c|c|c|c|}
\hline Mask wearing & $\begin{array}{c}\text { Have enough } \\
\text { masks and } \\
\text { always wear } \\
\text { masks in public }\end{array}$ & $\begin{array}{c}\text { Have enough } \\
\text { masks and wear } \\
\text { masks sometimes }\end{array}$ & $\begin{array}{c}\text { Have enough masks } \\
\text { but not wear masks } \\
\text { unless necessary } \\
\text { (hospital) }\end{array}$ & $\begin{array}{c}\text { Have insufficient } \\
\text { masks and } \\
\text { sometimes wear } \\
\text { masks }\end{array}$ & $\begin{array}{c}\text { Have insufficient } \\
\text { masks, seldomly } \\
\text { wear masks }\end{array}$ \\
\hline $\begin{array}{c}\text { Domestic college } \\
\text { students }\end{array}$ & $82.14 \%$ & $9.29 \%$ & $2.86 \%$ & $5.71 \%$ & $0 \%$ \\
\hline $\begin{array}{c}\text { CPSS score } \\
\text { students }\end{array}$ & 3.00 & 3.01 & 3.21 & 3.06 & $/$ \\
\hline Overseas college & $74.07 \%$ & $8.64 \%$ & $2.47 \%$ & $8.64 \%$ & $6.17 \%$ \\
\hline
\end{tabular}

\subsection{Psychological stress and study and entertainment}

The time dedicated to study in domestic and foreign college students was basically the same, mainly concentrated in the "most" and "almost half" groups, accounting for $87.14 \%$ and $80.25 \%$ respectively. Very few college students devoted all their time or little time to study. The relationship between study time and CPSS score also tends to be consistent. With the increase of study time, CPSS scores rises correspondingly, from 2.68 to 3.42 and from 2.79 to 3.01 , respectively. (Table 5)

Table 5. Study time and CPSS score

\begin{tabular}{|c|c|c|c|c|}
\hline & All the time & Most of the time & Almost half time & Little time \\
\hline $\begin{array}{c}\text { CPSS score of domestic } \\
\text { students }\end{array}$ & 3.42 & 3.04 & 3.03 & 2.68 \\
\hline $\begin{array}{c}\text { CPSS score of overseas } \\
\text { students }\end{array}$ & 3.01 & 2.92 & 2.89 & 2.79 \\
\hline
\end{tabular}

In addition to schoolwork, hobbies occupies a large proportion. About $49.46 \%$ of the respondents reported hobbies. The versatile extra-curricular activities of college students were important means to relieve their academic pressure. Seven recent studies[7] have studied specific types of activities (e.g., sports, arts, academic clubs, student union, etc.) and adolescents' academic performance. A positive correlation between adolescents' participation in activities and academic performance was confirmed.

The survey results in Table 6 shows that $54.84 \%$ of domestic college students and $43.75 \%$ of overseas college students devoted 1 to 5 hours a week to hobbies.
$30.65 \%$ of domestic college students spent 5 to 10 hours a week. $29.17 \%$ of overseas students, $12.9 \%$ of domestic college students and $20.83 \%$ of overseas students spent more than 10 hours a week. For those whose invested time was less than one hour, the CPSS scores of domestic college students and overseas college students were 3.64 and 3.24 respectively. However, the average CPSS of subjects who put in 1-5 hours a week decreased to 3.09 and 2.85 respectively. The number of people who spent 5-10 hours a week was reduced to 3; The CPSS scores of people who invested more than 10 hours a week rose slightly to 3.1 and 2.96, although still lower than the average score. 
Table 6. Time spent on hobbies in a week and CPSS score

\begin{tabular}{|c|c|c|c|c|}
\hline $\begin{array}{c}\text { Hobby time for } \\
\text { domestic students }\end{array}$ & $<1$ hour & $1-5$ hours & $5-10$ hours & $>10$ hours \\
\hline proportion & $1.61 \%$ & $54.84 \%$ & $30.65 \%$ & $12.9 \%$ \\
\hline CPSS score & 3.64 & 3.09 & 3 & 3.1 \\
\hline $\begin{array}{c}\text { Hobby time for } \\
\text { overseas students }\end{array}$ & $<1$ hour & $1-5$ hours & $5-10$ hours & $>10$ hours \\
\hline proportion & $6.25 \%$ & $43.75 \%$ & $29.17 \%$ & $20.83 \%$ \\
\hline CPSS score & 3.24 & 2.85 & 3.00 & 2.96 \\
\hline
\end{tabular}

\subsection{Psychological stress and social behavior}

In this study, the influence of college students' social behavior on psychological stress was discussed in four dimensions: communication with family, interaction with friends, participation in community activities and volunteer activities.

The communication with family members had a great impact on the psychological pressure of college students. The CPSS scores of domestic college students and overseas college students who communicated with family members frequently were 3.01 and 3.08 , respectively, which are lower than the average. In sharp contrast, the CPSS scores of college students who hardly communicated with their families were as high as 3.24 and 3.14 respectively in Table 7 . With increased communication frequency, students' CPSS scores showed a precipitous decline. For the students with the lowest CPSS scores, overseas students communicated with families more often than domestic students.

Table 7. Communication with Family and CPSS Score

\begin{tabular}{|c|c|c|c|c|c|}
\hline & Seldom & Occasional & Sometimes & Often & $\begin{array}{c}\text { Frequent (without } \\
\text { reservation) }\end{array}$ \\
\hline $\begin{array}{c}\text { Communication between } \\
\text { domestic students and their } \\
\text { families }\end{array}$ & $2.14 \%$ & $9.29 \%$ & $17.86 \%$ & $62.86 \%$ & $7.86 \%$ \\
\hline CPSS score & 3.24 & 3.02 & 3 & 3.01 & 3.06 \\
\hline $\begin{array}{c}\text { Communication between } \\
\text { overseas students and their } \\
\text { families }\end{array}$ & $2.47 \%$ & $13.58 \%$ & $28.4 \%$ & $49.38 \%$ & $6.17 \%$ \\
\hline CPSS score & 3.14 & 2.55 & 2.92 & 3.08 & 3.12 \\
\hline
\end{tabular}

There was no positive correlation between the behavior of communicating with friends and relieving stress. For those who had no close friends, the CPSS scores of domestic college students and overseas students were 2.96 and 2.69, respectively in Table 8, while those who have three or more close friends, their CPSS scores rise to 3.06 and 3.01 .

Table 8. Number of close friends and CPSS score

\begin{tabular}{|c|c|c|c|}
\hline $\begin{array}{c}\text { Number of close friends of } \\
\text { domestic students }\end{array}$ & 0 & $1-2$ & $3+$ \\
\hline CPSS score & 2.96 & 3 & 3.06 \\
\hline $\begin{array}{c}\text { Number of close friends of } \\
\text { overseas students }\end{array}$ & 0 & $1-2$ & $3+$ \\
\hline CPSS score & 2.69 & 2.94 & 3.01 \\
\hline
\end{tabular}

The CPSS scores of domestic college students and overseas students who participated in community activities were 3.11 and 2.98, respectively in Table 9, which were higher than those who were not involved in community activities (2.95 and 2.84). Among college students at home and abroad, the CPSS scores of volunteer groups are 3.08 and 2.68, among which the CPSS scores of domestic volunteer groups were higher than those of non-participants (3.01), while overseas students who participated in volunteer activities were lower than those of non-participants (2.99). 
Table 9. CPSS score of community activities and volunteer activities

\begin{tabular}{|c|c|c|}
\hline Club activity & Yes & No \\
\hline CPSS score of domestic students & 3.11 & 2.95 \\
\hline CPSS score of overseas students & 2.98 & 2.84 \\
\hline Volunteer activity & Yes \\
\hline CPSS score of domestic students & 3.08 & 3.01 \\
\hline CPSS score of overseas students & 2.68 & 2.99 \\
\hline
\end{tabular}

The psychological pressure of college students during the epidemic is quite common, but it is generally within control, and only a few students were under "severe stress". More than half of the students were "stressed", which deserves the attention of the students themselves and their guardians. By comparing the data of domestic college students and overseas college students, we can also see that psychological stress of overseas students ramped up with longer study time while the pressure of domestic students gradually came down with the more study time. This may be affected by factors such as academic burden and cultural environment.

\section{DISCUSSION}

\subsection{Psychological stress and attention to epidemic information}

The survey results demonstrated that compared to the lower grade students, the students in higher grades displayed more interest and enthusiasm for epidemic news, which may be related to the stronger sense of social responsibility of the senior students. However, with the increase of study period, the proportion of more overseas students paid attention to news only for a short time, which may reflect their relatively heavy academic workload.

By comparing and analyzing the relationship between the authenticity of news channels and college students' psychological pressure perception, the results showed that community flyers were the best news channel to reduce college students' pressure. The CPSS scores of CCTV news and online news were lower than the overall average score. Therefore both of them had a decompression effect on college students. News from we media and information from relatives and friends were often exaggerated, which accentuated psychological pressure.

Among all information channels, newspapers had the highest CPSS score. Among the surveyed people who read newspapers, $91.67 \%$ read newspapers mainly by browsing headlines. As a kind of paper media, pure text was lack of emotion, and careless browsing could lead to wrong judgment, which would add psychological pressure. Therefore, it is suggested that college students should read newspapers reasonably and rationally, and avoid being biased.

It is necessary for the college student to keep up with the current events, which helps cultivate the social responsibility and is of great benefit to their personality and academic development. However, during the epidemic, attention should be paid to adjust the time allocation to information source depending on the individual psychological pressure.

\subsection{Psychological stress and mask wearing}

Mask wearing is the most effective way to prevent the virus transmission. The practice of mask wearing is closely related to local customs. Asians are generally more acceptable to the idea of using masks to protect human health, while most westerners resist wearing masks by nature. Some people believe that only people with severe infectious diseases or terminal illnesses need to wear masks. Some countries even have laws specifically prohibiting wearing masks to avoid covering the face. Mask wearing is strongly influenced by culture, and it also have repercussions on people's anxiety.

Psychological stress is closely related to mask wearing. Even if there are enough masks, college students who chose to wear masks less often had higher psychological pressure. The CPSS scores of domestic students and overseas students who wore masks every time they go out were the lowest $(3,2.97)$; the college students wearing masks sometimes scored second (3.01, 2.9)., students who wore masks only when they went to high-risk places (such as hospitals) had the highest psychological pressure, with CPSS scores as high as 3.21 and 3.18. Wearing a mask can give people a sense of security against viruses, thus relieving psychological stress.

CPSS score has nothing to do with whether there are enough masks. As long as masks were worn consciously, fear and psychological stress were reduced. As shown in Table 3, in all scenarios, the people with the highest CPSS score were those who have enough masks but seldomly wore them when going out (3.21 and 3.18). Irregardless of the mask stock, the CPSS score diminished to below 3.20 as long as masks were worn consciously and frequently. 
Based on our analysis results, in order to relieve psychological pressure and prevent infection, masks should be worn as much as possible. With the large-scale resumption of manufacture, the production capacity of masks has steadily increased, which also helps protecting people's health and relieving anxiety. For overseas students, $6.17 \%$ did not wear a mask. Considering the local culture, the psychological pressure of those who had enough masks but hardly wore them was 3.18, and most of them wore masks to relieve their psychological pressure.

\subsection{Psychological stress and study and entertainment behavior}

Among the respondents, $4.29 \%$ reported that academic study took up all their time. $46.24 \%$ of the students said that schoolwork occupied most of their time. The proportion of study time of college students was almost linearly related to their psychological stress. The more time was invested in assignments, the greater was the psychological pressure. The average psychological pressure of groups who only allocate about half of their schoolwork was better. In conclusion, long study time may aggravate psychological pressure during the epidemic.

The research showed that the the student's anxiety level increased with their grades [8]. The younger students generally lack communication with others, and devote all their energy and time to study, which may it harder to relax, resulting in an adverse effect on the physical and mental health of college students. Teenagers with low self-esteem are at greater risk of depression, especially in the face of stressful life events. It is essential to figure out efficacious prophylactic measures to improve self-esteem and scale down the risk of depression [9].

In addition, there is a negative correlation between the time spent on hobbies and psychological stress. Therefore, proper time assigned to hobbies as the adjustment of work and study can obviously improve college students' psychological anxiety.

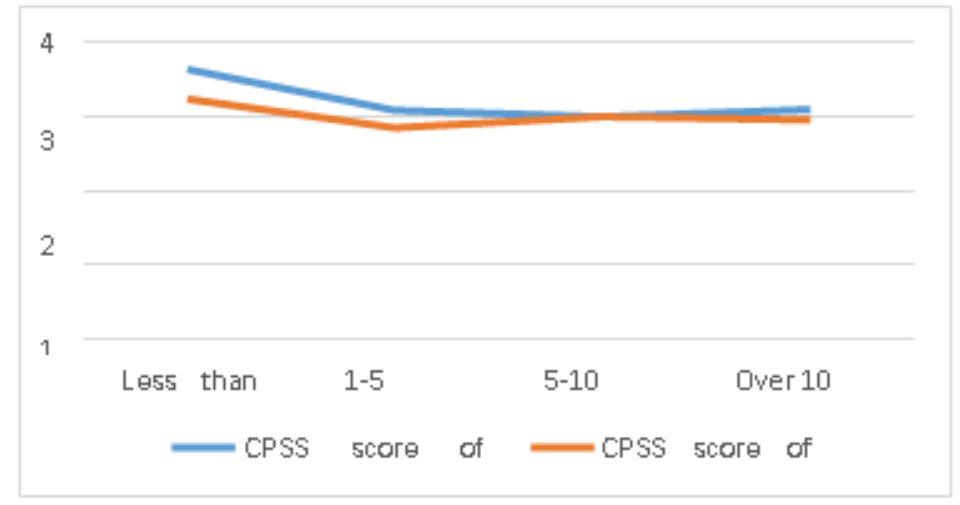

Figure 3 Statistics of hobby time of college students at home and abroad during the epidemic period

\subsection{Psychological stress and social activities}

People have a natural desire to socialize. During the epidemic, people were generally isolated at home, which greatly limited the social activities among people.

The results of communication between family and friends showed that with the increase of communication frequency, students' CPSS scores displayed a sharp decline initially followed by a gentle recovery. Therefore, it is necessary for college students to communicate with family and friends reasonably and frequently during the epidemic, which can significantly reduce psychological pressure. However, it also demonstrated that when students talked with their families without reservation, their CPSS rises to 3.06 and 3.12. It is suggested that college students need to find a balanced midland to avoid pressure.
During the epidemic, community activities and volunteer activities were not found to significantly relieve anxiety of domestic students in our study. Many relevant tasks were arduous and challenging which led to anxiety. With regard to online activities, students did not feel the same level of participation or satisfaction, which weakens the incentives to be involved. On the other hand, overseas students reported relief of psychological stress after joining the volunteer activities. Participance in social activities helps teenagers build self-confidence, selfesteem and learn new skillsets.

Our data analysis are not discouraging college students' making friends or participating in community volunteer activities, as college students are not supposed to focus on their own pressure, but also lay their eyes on the social responsibility. Volunteer activities are beneficial in the long run. Many previous studies have supported the positive correlation between youth volunteer services and their self-esteem enhancement [10]. 


\section{CONCLUSION}

In this paper, 140 domestic college students and 81 overseas college students were investigated by questionnaires, and the correlation between psychological stress and various behaviors was analyzed by CPSS. The results showed that there was no significant difference in pressure perception between domestic college students and foreign students except for news channel $(p<0.05)$. Studies have shown that consistent mask wearing, moderate understanding of epidemic news, participation in hobbies and interaction with family members could effectively relieve college students' psychological pressure. In the information age, people are faced with various news channel choices, among which official news, internet videos and community news have the most decompression effect. College students need to deal with the contradiction of online information rationally and think critically as much as possible. In this epidemic, mask wearing was not only an effective way to block the virus spread physically, but also impacted positively on people mentally. With the recovery and improvement of national mask production capacity, masks should be worn consistently for both physical and mental health. At the same time, the epidemic was also a rare opportunity to cultivate hobbies and strengthen family members' bond. The results also pointed out that the behavior of making friends and participating in volunteer community activities during the epidemic may aggravate the psychological pressure of college students, which should be taken seriously and treated rationally by college students. As an integral part of society, college students should take good care of themselves during the epidemic. Meanwhile we should realize our social value by assuming our liabilities. College students should adopt a long-term view and find a suitable balance between themselves and society while relieving psychological pressure scientifically.

\section{AUTHORS' CONTRIBUTIONS}

This paper is completed together by Yuhan Zhan and Junhua Zhang. Yuhan Zhan is responsible for data acquisition, wrote the manuscript. Junhua Zhang is responsible for experimental design, analysed data, wrote the manuscript, contributed to revising and editing.

\section{ACKNOWLEDGMENTS}

Great gratitude is extended to our teachers for their professional guidance and genuine assistance in this paper.

\section{REFERENCES}

[1] Catrin Sohrabia, Zaid Alsafib, Niamh O’Neilla, World Health Organization declares global emergency: A review of the 2019 novel coronavirus
(COVID-19) Overseas Journal of Surgery. 2020(76) 71-76.

[2] Chang Jinghui, Yuan Yuxin, Wang Dong. Analysis of mental health status and influencing factors of college students under novel coronavirus epidemic [J/OL]. Journal of Southern Medical University: 16[2020-03-14].

http://kns.cnki.net/kcms/detail/44.1627.r.20200303. 1404.004.html.

[3] Wang Ya. Study on anxiety level of college students and its influencing factors during epidemic prevention and control [J]. Journal of Teacher Education, 2020,7(03):76-83.

[4] Arnett, J.J., 2000. Emerging adulthood: A theory of development from the late teens through the twenties. Am. Psychol. 55, 469

[5] Auerbach, R.P., Mortier, P., Bruffaerts, R., Alonso, J., Benjet, C., Cuijpers, P., Demyttenaere, K., Ebert, D.D., Green, J.G., Hasking, P., Murray, E., Nock, M.K., Pinder-Amaker, S., Sampson, N.A., Stein, D.J., Vilagut, G., Zaslavsky, A.M., Kessler, R.C., Collaborators, W.W.-I., 2018. WHO world mental health surveys overseas college student project: prevalence and distribution of mental disorders. J. Abnorm Psychol. 127, 623-638.

[6] Zhao Anna, Li Yan, Sun Lu. Analysis of the relationship between physical fitness and stress of nurses in neurology department by TCM identification theory [J]. Chinese Journal of Practical Medicine, 2018(20):195-196.

[7] Amy Feldman Farb a, Jennifer L. Matjasko Recent advances in research on school-based extracurricular activities and adolescent development Developmental Review 32 (2012) 1-48.

[8] Burns, E. C., Bostwick, K. C. P., Collie, R. J., \& Martin, A. J. (2019). Girls' disengagement: Latent growth modelling of trajectories and the role of teacher and peer support. Journal of Youth and Adolescence, 48, 979e995.

[9] Fiorilli, C., Capitello, T. G., Barni, D., Buonomo, I., \& Gentile, S. (2019). Predicting adolescent depression: The interrelated roles of self-esteem and interpersonal stressors. Frontiers in Psychology, 10, 1-6. doi: 10.3389/fpsyg.2019.00565

[10] Astin, A. W., Sax, L. J., \& Avalos, J. (1999). Longterm effects of volunteerism during the undergraduate years. Review of Higher Education, 22, 187-202. Retrieved from https://digitalcommons.unomaha.edu/cgi/viewconte $\mathrm{n}$ 